\title{
Preparation and Characterization of Activated Carbon from Bagasse and Jute Fibre for Heavy Metal Adsorption
}

\author{
Md. Shazzad Hossain* ${ }^{1}$, Farzana Khan Rony*2, Sazia Sultana*², Md.Humayun Kabir ${ }^{* 2}$, \\ Sumaya F. Kabir* ${ }^{1}$, Samina *Ahmed ${ }^{* 2}$ \\ ${ }^{1}$ Department of Applied Chemistry \& Chemical Engineering, University of Dhaka, Bangladesh ${ }^{2}$ Bangladesh \\ Council of Scientific and Industrial Research, Dhaka, Bangladesh
}

\begin{abstract}
Over the past few years, activated carbon (AC) has attained significant attention as an efficient adsorbent for heavy metal (lead, cadmium, chromium etc.) removal. In Bangladesh, bagasse and jute fibre are the two most potential raw materials for producing activated carbon due to their high availability and low cost. The activated carbon was produced by thermal treatment method. The produced AC were characterized using FTIR, XRD, SEM etc. Batch experiments under agitation was also carried out for adsorption of heavy metals and then characterized using AAS (Atomic Adsorption Spectroscopy). Adsorption with commercially available activated carbon was also done to use as standard. Among all ACs produced in this study, the highest percentage removal of heavy metals which were $\mathrm{Cr}^{3+}$ and $\mathrm{Cd}^{2+}$ was at $57.06 \%$ and $43.01 \%$ respectively for $\mathrm{J}-400$ ( AC produced from jute fibre at $400^{\circ} \mathrm{C}$ ). This obtained value was $16.6 \%$ and $12.9 \%$ higher in comparison to Commercially available Activated carbon for $\mathrm{Cr}^{3+}$ and $\mathrm{Cd}^{2+}$ respectively
\end{abstract}

Keywords: Adsorption, Activated carbon, dyes, isotherm

\section{INTRODUCTION}

Activated Carbon(AC) is an excellent adsorbent with high porosity, internal surface area and pore volume(Girgis). It may be visualized as foam solid that has a large surface area with rigid particle structure of relatively small volume (Bansal, Aggarwal et al. 2002, Asadullah, Asaduzzaman et al. 2010). The large surface area results in a high capacity for absorbing chemical and contaminants from gases and liquids(Dula, Siraj et al. 2014). The adsortive property stems from the extensive internal pore structure that develops during the activation process(Cuhadar 2005). There are two main methods of producing AC; thermal activation and chemical activation(Asadullah, Rahman et al. 2007, M.S. Shamsuddin 2016). In thermal activation process any carbonaceous material undergo decomposition in absence of air causes evolution of tarry and gaseous products at relatively low temperature and a solid carbon produced as a final product(Foo). However, in chemical activation process, the carbonaceous material is mixed with activating agents. This activating agent restricts the formation of tar and creates more internal pores through dehydration reaction occur at significantly lower temperature (Yagsi 2004).To produce activated carbon different carbonaceous materials of organic origin which are rich in carbon are usually used. However, choice of raw materials is an important factor to produce low cost activated carbon. For instance, in context of Bangladesh,agriculutural biomass e.g.; bagasse, jute fibre, kenaf are suitable raw materials to produce low cost activaed carbon.Asadullah et al.(Asadullah, Rahman et al. 2007)has produced activated carbon by thermal activation method from jute fibre and used the produced activated carbon to remove dye from aqueous solution(Asadullah, Asaduzzaman et al. 2010). Another study has also reported by Asadullah et al. to produce activated carbon from jute stick and used to remove arsenic from water (Asadullah, Jahan et al. 2014).Ramesh et al. (Ramesh, Rajalakshmi et al. 2017)also used jute fibre to activated carbon to use as hydrogen storage.Foo et al. used bagasse as raw material for production of activated carbon using microwave heating treatment for the adsorptive 
treatment of semi-aerobic landfill leachate(Foo).Another study was reported by Girgis et al. using sugarcane bagasse as raw material in producing activated carbon(Girgis). Shamsuddin et al. prepared AC by chemical activation method from kenaf core fibre(M.S. Shamsuddin 2016).In Bangladesh, Industrial pollution is a growing concern of the present days. Untreated Effluents mostly from tanneries contain heavy metals, dyes, oils etc are directly discharged into rivers and streams (McKee, Unal et al. 2005). This study aims to produce low cost activated carbon from jute fibre by thermal activation method which could be a used as a potential adsorbent to treat industrial polluted effluents.

\section{MATERIALS AND METHODS}

\subsection{Raw Materials}

Bagasse and jute fibres are collected from local farmers and the local market. Sodium Hydroxide was purchased from Merck KGaA, (Germany). It's index no is 011- -0200 6. Chromium standard solution was bought from SIGMA ALDRICH. Cadmiumstandard solutionwas also bought from SIGMA ALDRICH.2\%Nitric acid was prepared from $65 \%$ nitric acid which was purchased from SIGMA ALDRICH.

\subsection{Preparation of Activated carbon}

\subsubsection{Pretreatment of Raw materials}

Jute fibre was collected from local farmers and baggase was collected from the local market. Both the raw materials were sorted and washed with water separately to remove sand and dirt. Then the raw materials were dried under sunlight for $48 \mathrm{hrs}$ followed by drying at $110^{\circ} \mathrm{C}$ for $2 \mathrm{hrs}$ in an oven to remove moisture. Then, the dried samples were cut into small pieces for increasing surface area for proper charring.

\subsubsection{Charring of dried raw materials}

The dried raw materials were pyrolysed in a furnace at a rate of $8^{\circ} \mathrm{C}$ per minute from room temperature to a temperature range 400,450 and $500^{\circ} \mathrm{C}$ respectively and maintained at this temperature for 10 mins. The produced char was transferred from the furnace after $24 \mathrm{hrs}$. Then the obtained chars were crushed and sieved.

\section{Table 1: Charring condition of dried raw materials}

\begin{tabular}{|c|c|c|c|c|c|c|c|}
\hline $\begin{array}{c}\text { Rawmate } \\
\text { rial }\end{array}$ & $\begin{array}{c}\text { Wt.ofthe } \\
\text { sample (gm) }\end{array}$ & $\begin{array}{c}\text { PyrolysisTem } \\
\text { perature }\left({ }^{\circ} \mathbf{C}\right)\end{array}$ & $\begin{array}{c}\text { Stayin } \\
\text { gTime } \\
\text { (Mins) }\end{array}$ & $\begin{array}{c}\text { Reaction } \\
\text { Rate } \\
\left({ }^{\circ} \mathbf{C} / \text { Min) }\right.\end{array}$ & $\begin{array}{c}\text { Wt.ofthech } \\
\text { ar } \\
\mathbf{( g m})\end{array}$ & $\begin{array}{c}\text { Yield } \\
(\%)\end{array}$ & $\begin{array}{c}\text { Sample } \\
\text { name }\end{array}$ \\
\hline \multirow{2}{*}{ Jute Fibre } & 50 & 400 & 10 & 8 & 5.6 & 11.2 & J-400 \\
\cline { 2 - 8 } & 50 & 450 & 10 & 8 & 5.2 & 10.4 & J-450 \\
\cline { 2 - 8 } & 50 & 500 & 10 & 8 & 4.4 & 8.8 & J-500 \\
\hline
\end{tabular}

\subsubsection{Activation of the char}

Activation refers to the change of raw carbon material to the more porous material. The higher the porosity, the better the adsorption capacity. That'swhy the raw carbon material is activated for increasing is adsorption capacity. The crushed char were activated by sodium hydroxide. The activation was carried out by impregnation of the char with sodium hydroxide for $24 \mathrm{hrs}$. The preweighted sodium hydroxide and charwasmixed with distilled water by a magnetic stirrer. The activation was carried out at room temperature. 


\subsubsection{Washing of Activated Carbon}

After the completion of activation, the materials werewashed with distilled water several times to remove the activating agent. Finally, the activated carbon was dried at $110^{\circ} \mathrm{C}$ until it gains a fixed mass. Then the activated carbons were transferred into a desiccator for proper desication. AC was kept dry until it's application.

\subsection{Characterization techniques}

\subsubsection{Fourier Transform infrared spectrophotometer (FT-IR)}

FT-IR-spectra of the samples were recorded on an FT IR spectrophotometer (SHIMADZU, Model MIRacle 10) in the wavelength range of $4000450 \mathrm{~cm}^{1}$, resolution: $4 \mathrm{~cm}^{1}$,scan 30. Approximately $25 \mathrm{mg}$ of samples were ground with mortar and then was spread over the crystal of ATR accessories. The two knobswere tightly rounded to hear a click sound and the spectra were recorded.

\subsubsection{X-ray Diffractometer (XRD)}

XRD patterns of the samples were recorded by an $x$ ray diffractometer (Ultima IV, Rigaku Corporation, Japan) at room temperature. Prior to XRD analysis, the samples were grounded into fine powders using mortar pestle. CuK $\alpha$ radiation $(\lambda=0.154 \mathrm{~nm})$, from a broad focus copper tube operated at $40 \mathrm{KV}$ and $40 \mathrm{~mA}$, was applied to the samples for measurement. The XRD pattern of the samples was measured in the continuous scanning mode with the scan speed of $3^{\circ} \mathrm{C} / \mathrm{min}$ and in the scan range of 0 to 50 . Braggs law was used to compute the basal spacing of the samples.

\subsubsection{Scanning Electron Microscopy (SEM)}

The morphology of the samples was analysed by an analytical scanning electron microscope (JEOL JSM6490LA, Tokyo, Japan) operated at an accelerating voltage of $20 \mathrm{KV}$ in the back scattered electron mode. In order to get further insight into the morphology,micro structures of the samples were examined in various magnification.

\subsection{Application of the produced activated carbon}

The produced activated carbons were used to absorb chromium $\left(\mathrm{Cr}^{3+}\right)$ and cadmium $\left(\mathrm{Cd}^{2+}\right)$ from a standard solution of chromium and cadmium.For this purpose, the calibration curve was produced by spectrophotometric method. Standard solutios of heavy metals which are $\mathrm{Cr}$ and $\mathrm{Cd}$ of different concentrations $(0.2,0.4,0.6,0.8,1,1.5$ ppm) were made and their absorbance was determined by Atomic Absorption Spectroscopy (AAS).

\subsubsection{Atomic Absorption Spectroscopy:}

Concentration of the heavy metals before and afteradsorption was determined using AAS (Analytik jena 350). The technique makes use of the atomic absorption spectrum of a sample in order to assess the concentration of a specific analyte within it. It requires standard with known analyte concentration $(0.2,0.4,0.6,0.8,1.1 .5 \mathrm{ppm})$ to establish the relation between the measured absorbance and the analyte concentration and therefore relies on the Beer-Lambert law.

The parameters changed for determining the optimum condition during the adsorption process are given below.

\subsubsection{Types of adsorbent}

To find out the best suitable adsorbent, $25 \mathrm{ml}$ of $1 \mathrm{ppm} \mathrm{Cr}^{3+}$ and $\mathrm{Cd}^{2+}$ solution was taken for each batch of adsorbent. Same amount of adsorbents $(400 \mathrm{mg})$ was added at room temperature. $\mathrm{pH}$ of the solution was same. The solution was shaked for $5 \mathrm{hrs}$ at $150 \mathrm{rpm}$ in each case.

\subsection{3 pH of the solution}

To study the influence of $\mathrm{pH}$ on the adsorption by the best suitable adsorbent, $25 \mathrm{ml}$ of $1 \mathrm{ppm}$ solution of $\mathrm{Cr}^{3+}$ and $\mathrm{Cd}^{2+}$ was taken in each of the ten reagent bottles. $\mathrm{pH}$ of the solutions was adjusted from 2 to 10 using $2 \mathrm{M}$ 
$\mathrm{NaOH}$ solution. $400 \mathrm{mg}$ of same adsorbent were added in each of the reagents bottles. Then all the reagents bottles were placed in an orbital shaker for shaking about 5 hours at $150 \mathrm{rpm}$.

\subsubsection{Adsorption dosage}

The effect of different adsorbent dose in the range $200-600 \mathrm{mg}$ was experimented. Initial concentration in

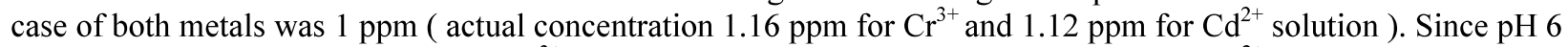
showed best percentage removal for $\mathrm{Cr}^{3+}$ and $\mathrm{pH} 8$ showed best percentage removal for $\mathrm{Cd}^{2+}$ in earlier experiment, here $\mathrm{pH}$ of the $\mathrm{Cr}^{3+}$ solution and $\mathrm{Cd}^{2+}$ solution was maintained at 6 and 8 respectively. 25 ml solution was taken in each of the 10 reagent bottles and all the reagent bottles were placed in an orbital shaker for $5 \mathrm{hrs}$ at $150 \mathrm{rpm}$.

\subsubsection{Contact Time}

We studied the effect of contact time on the adsorption for a time varying from 1 to 6 hours. 25 ml solution of $\mathrm{Cr}^{3+}$ was taken in each of five reagents bottles and $25 \mathrm{ml}$ solution of $\mathrm{Cd}^{2+}$ in each of the another five reagent bottles. $\mathrm{pH}$ of the $\mathrm{Cr}^{3+}$ solution was maintained at 6 and for $\mathrm{Cd}^{2+}$ solution; it was 8 as the best suitable condition. 400 mg adsorbent (J-400) was added in each of the bottles. Then all the bottles were placed in an orbital shaker for different time period at $150 \mathrm{rpm}$.

During the change of every parameter, the removal yield of chromium and cadmium were calculated by the following relationship:

\section{Removal yield \% $=\left(\begin{array}{ll}C_{0} & C_{e}\end{array}\right) 100 / C_{0}$}

where $\mathrm{C}_{0}$ and $\mathrm{C}_{\mathrm{e}}$ are the initial and final (equilibrium ) concentrations (ppm) of the metal of interest respectively. The adsorption capacity, $\mathrm{q}_{\mathrm{e}}$ at any time was calculated by:

$$
\mathbf{q}_{\mathrm{e}}=\left(\mathbf{C}_{0}-\mathbf{C}_{\mathrm{e}}\right) \mathrm{V} / \mathbf{W}
$$

where $\mathrm{C}_{0}$ and $\mathrm{C}_{\mathrm{e}}$ are the initial and concentrations (ppm) at any time of the metal, $\mathrm{V}$ is the volume of the test solution and $\mathrm{W}$ is the mass of the adsorbent used in adsorption.

\subsection{Adsorption isotherm}

Adsorption isotherm is one of the most important characteristics to describe the adsorption behavior. It also describes relationship between the amount of adsorbate adsorbed on the adsorbent and the concentration of the dissolved adsorbate in the liquid at equilibrium(Kamal 2014). Among many isotherm models, the Langmuir isotherm and the Freundlich isotherm were employed in this study to observe the adsorption behavior. Adsorption isotherm of $\mathrm{Cr}^{3+}$ was carried out at room temperature using optimum experimental conditions ( $\mathrm{pH}$ 6, 5 hours contact time) with initial concentration of $1 \mathrm{ppm}^{3+}$ solution.

\subsubsection{Langmuir Isotherm}

Langmuir isotherm model is well known isotherm model for monolayer adsorption. It assumes that the adsorption takes place at specific homogeneous sites within the adsorbent. The linear form of Langmuir isotherm can be represented with the following equation:

Where,

$$
\frac{C_{e}}{q_{e}}=\frac{C_{e}}{q_{\max }}+\frac{1}{\mathbf{q}_{\max } K_{L}}
$$

$\mathrm{q}_{\mathrm{e}}=$ equilibrium adsorbate concentration on the adsorbent $(\mathrm{mg} / \mathrm{g})$;

$\mathrm{C}_{\mathrm{e}}=$ equilibrium concentration of the adsorbate on the solution (ppm); 
$\mathrm{q}_{\max }=$ maximum adsorption capacity of the adsorbent $(\mathrm{mg} / \mathrm{g})$;

$\mathrm{K}_{\mathrm{L}}=$ Langmuir adsorption constant related to the free energy of adsorption $(\mathrm{L} / \mathrm{g})$.

\subsubsection{Freundlich Isotherm}

The Freundlich isotherm is a popular model used to describe heterogeneous adsorption process, i.e. adsorption that takes place on a heterogeneous surface through a multilayer adsorption mechanism. Freundlich isotherm is expressed by the equation:

$$
\mathbf{q}_{\mathrm{e}}=\mathbf{K}_{\mathrm{F}} \mathbf{C}_{\mathrm{e}}^{1 / \mathrm{n}}
$$

\section{RESULTS AND DISCUSSION}

\section{$3.1 \quad$ FT-IR spectra of prepared activated carbon}

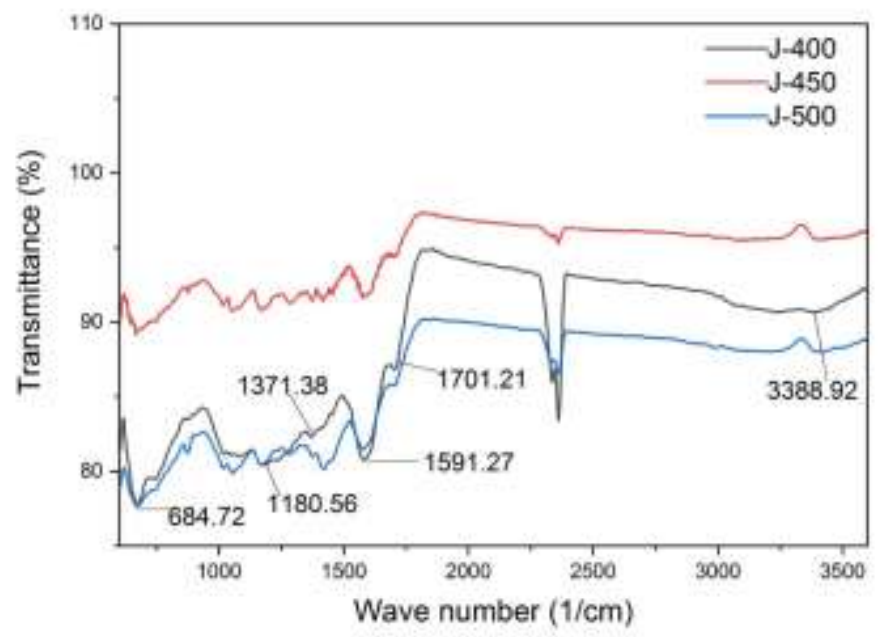

Figure 1: FTIR spectra of ACs produced from jute fibre at different temperature

Table 2: FTIR band position and their corresponding assignment.

\begin{tabular}{|c|c|}
\hline Observed Band position $\left(\mathrm{cm}^{-1}\right)$ & Corresponding assignments \\
\hline $3360-3398$ & Stretch vibration of $-\mathrm{OH}$ group(Zhang, Wang et al. 2018) \\
\hline $3350-3400$ & $\begin{array}{l}\text { Stretch vibration of -NH group in amines and amides(Auta and } \\
\text { Hameed 2011) }\end{array}$ \\
\hline $2326-2363$ & Stretch vibration of $\mathrm{C} \equiv \mathrm{C}$ bond of Alkyne(Auta and Hameed 2011) \\
\hline $1570-1592$ & $\begin{array}{l}\text { Stretch vibration of } \mathrm{C}=\mathrm{C} \text { in alkene(Auta and Hameed 2011), bending of } \\
\mathrm{C}=\mathrm{C} \text { in aromatics }\end{array}$ \\
\hline $1365-1371$ & $\begin{array}{l}\text { Bending vibration of } \mathrm{C}-\mathrm{H} \text { in alkane(Zhang, Wang et al. 2018), N-O } \\
\text { symmetric stretch in nitro group }\end{array}$ \\
\hline $1180-1203$ & Stretching of C-O in alcohol, carboxylic acid group \\
\hline $670-684$ & Stretching of C-H group in alkane, alkene and aromatics \\
\hline
\end{tabular}


Figure 1shows the FTIR spectra of produced activated carbons (J-400, J-450 and J-500) and the corresponding peaks are presented inFigure 1: FTIR spectra of ACs produced from jute fibre at different temperature

Table 2. From Figure 1 the peaks associated with $\mathrm{O}-\mathrm{H}, \mathrm{C}-\mathrm{H}, \mathrm{C}-\mathrm{C}, \mathrm{C}=\mathrm{C}, \mathrm{C}-\mathrm{O}$ and $\mathrm{C} \equiv \mathrm{C}$ vibrations are identified (Table 2). The presence of these functional groups onthe produced ACs agree with the findings of Auta and Hameed(Auta and Hameed 2011). Auta and Hameed produced activated carbon from waste tea and identified the presence of hydroxyl, alkyl and carbonyl functional groups. They explained that these functional groupscan be dissociate and become negatively charged to produce electrostatic attraction between the adsorbent and positively charged metal ions(Auta and Hameed 2011). They concluded that the presence of numerous and varieties of functional groups in the activated carbon can contribute to higher adsorption activities.

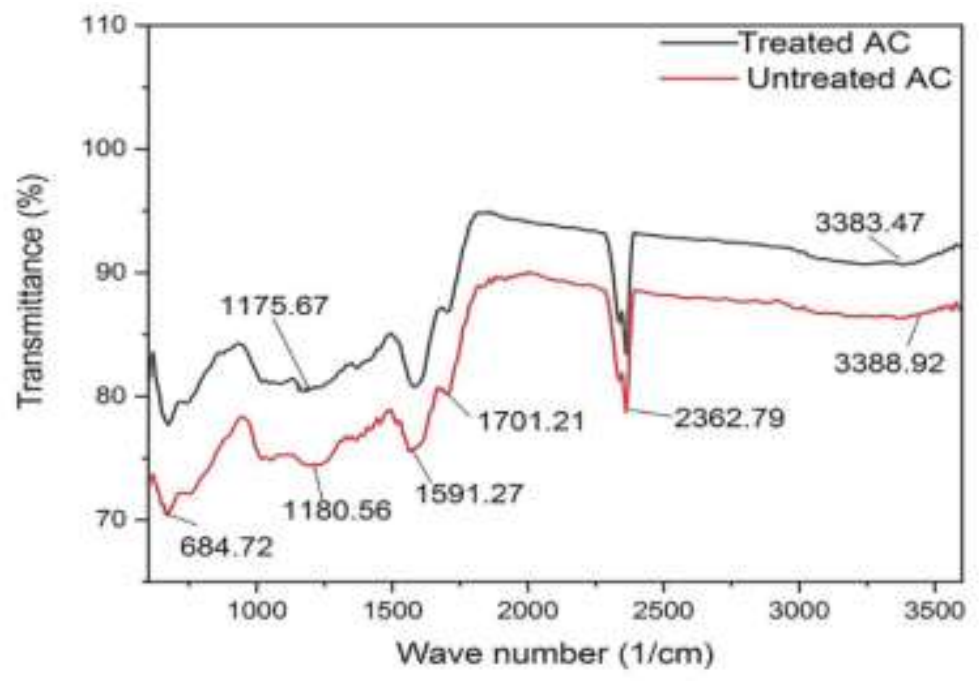

Figure 2: Comparison of FTIR spectra of J-400 before and after adsorption

Figure 2 shows the comparison of the FTIR spectra of J-400 before and after adsorption of heavy metals (Cr and Cd). No major difference in FTIR spectra were observed before and after adsorption of heavy metals. This observation indicates that there is no chemical bonding/ change occurred during adsorption.

\section{$3.2 \quad \mathrm{X}$-ray diffraction spectroscopy:}

Figure 3represents the XRD pattern of the produced AC ( $\mathrm{J} \mathrm{400).} \mathrm{Two} \mathrm{broad} \mathrm{diffraction} \mathrm{peaks} \mathrm{at} 26.6^{\circ}$ and $43.5^{\circ}$ were observed which could be attributed to the presence of carbon and graphite(Bouchelta, Medjram et al. 2008). Moreover, the broad diffraction indicates the amorphous nature and low graphitization(Fan, Yang et al. 2014, Chen, Peng et al. 2015, Zhang, Wang et al. 2018). 


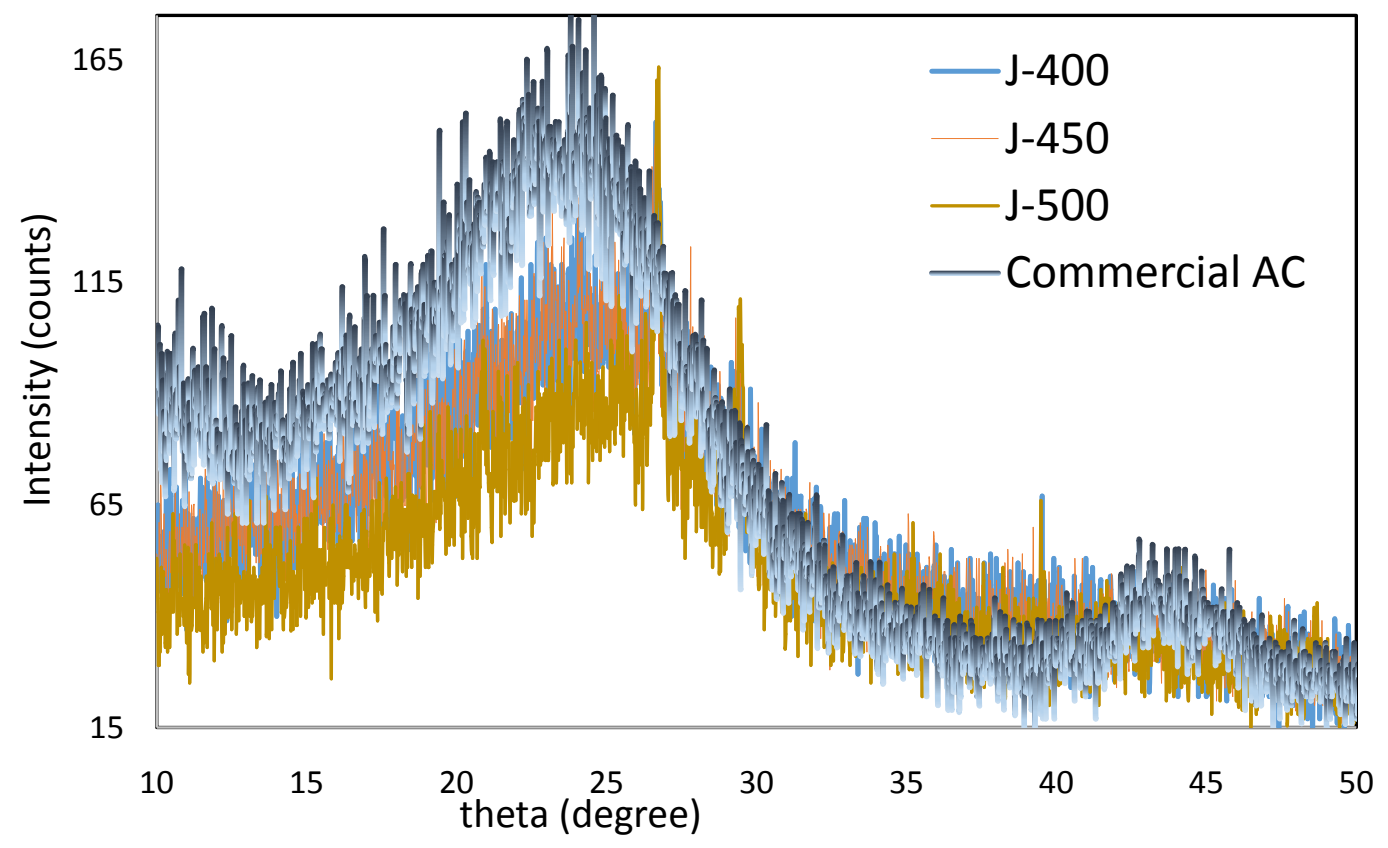

Figure 3: Comparison of ACs produced from jute fibre with commercial AC

\subsection{SEM images of the produced activated carbon}

Figure 4represents the SEM images of the AC (J-400) before and after adsorption.
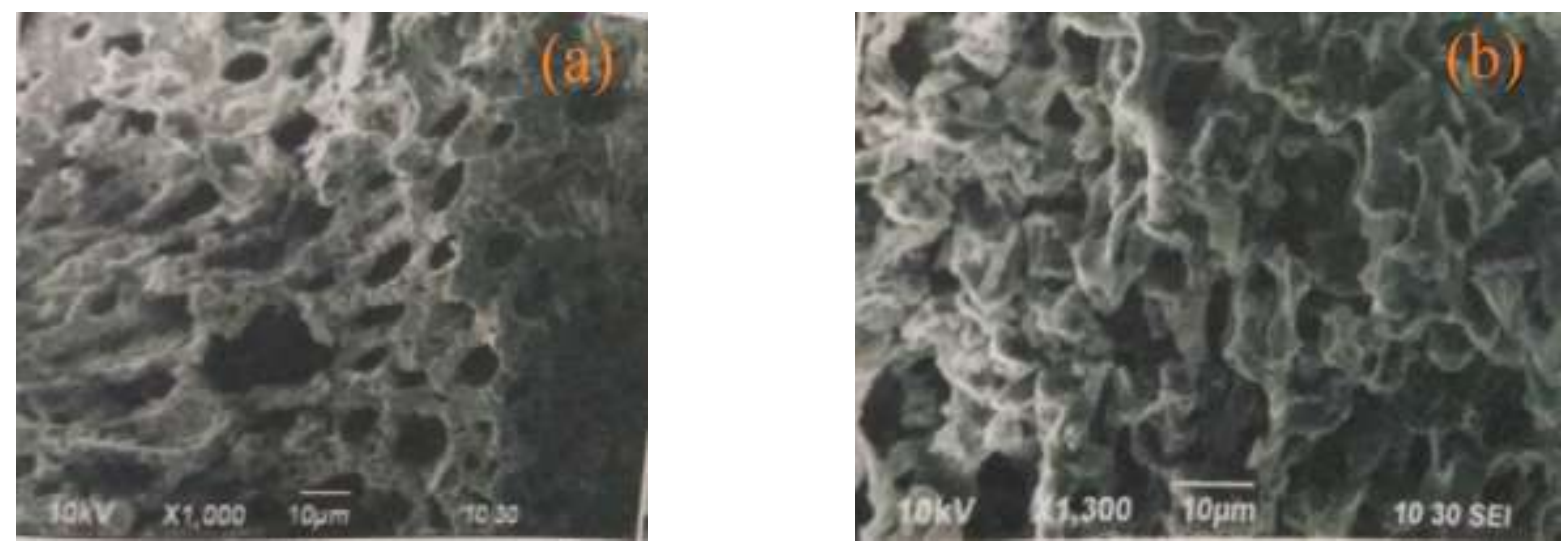

Figure 4: SEM images of AC (J-400) before (a, b) and after (c, d) adsorption

SEM image before adsorption (Figure 4a) showed the porosity with small openings on the surface of the AC which enhance the diffusion of heavy metals during adsorption. Whereas, Figure 4b shows that the porosity had decreased after adsorption indicated that most of the pores were filled with the heavy metals. 


\subsection{Atomic Absorption Spectroscopy:}

\subsubsection{Calibration Curve}

The calibration curve was produced by spectrophotometric method. For this purpose, standard solutios of heavy metals which were $\mathrm{Cr}^{3+}$ and for $\mathrm{Cd}^{2+}$ of different concentrations were made and their absorbance were determined by Atomic Absorption Spectroscopy (AAS).
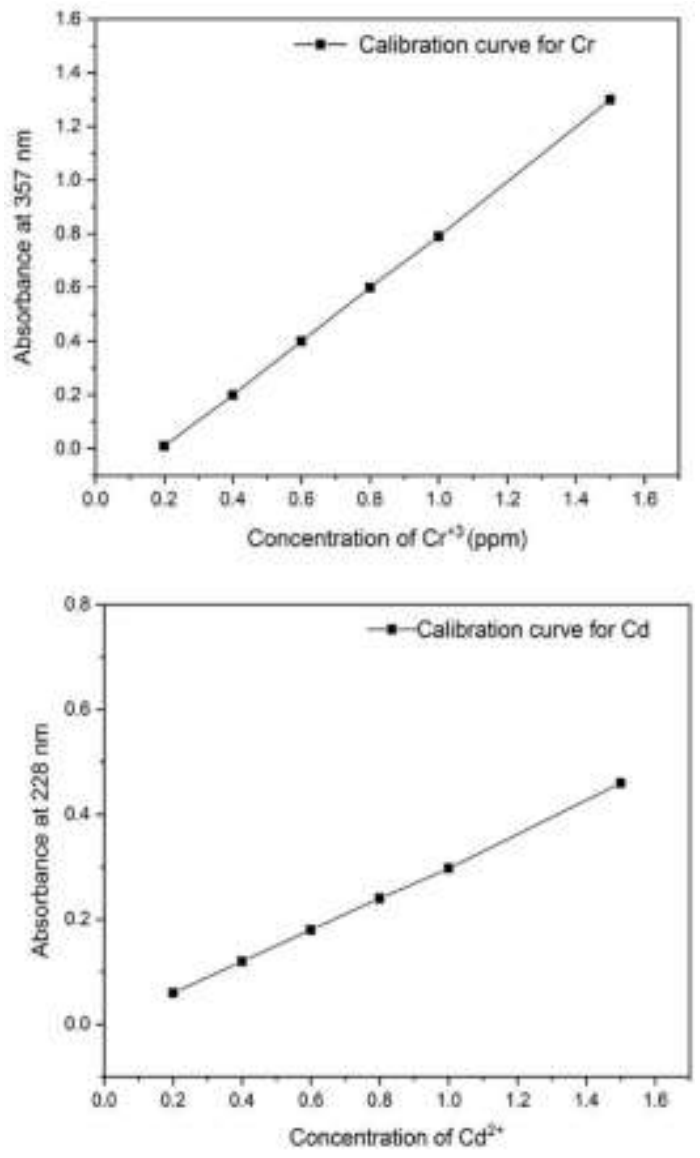

Figure 5: Calibration curve for $\mathrm{Cr}^{3+}$ and $\mathbf{C d}^{2+}$ solution

The $\mathrm{R}^{2}$ value of the $\mathrm{Cr}^{3+}$ calibration curve obtained from Figure 5and of the $\mathrm{Cd}^{2+}$ calibration curve obtained from figure 4.10 is .9997 and .9985 respectively.

\subsubsection{Adsorption capacity of produced AC:}

AC's (J 400, J 450, J 500) were used to adsorb heavy metals from the pure solution of heavy metals $\left(\mathrm{Cr}^{3+}\right.$ and $\mathrm{Cd}^{2+}$ ) to get the best adsorption result. A commercially available activated carbon (CAC) was used as standard for comparison.

The percentage removal of heavy metal ions using produced Ac's and the CAC are presenting in Figure 6. All ACs showed better adsorption for Cr in comparison to Cd. For instance, J-400 showed $14.05 \%$ higher adsorption 
for $\mathrm{Cr}$ in comparison to $\mathrm{Cd}$ which is predicted to be due to the greater atomic radius of $\mathrm{Cd}^{2+}\left(0.97 \mathrm{~A}^{\circ}\right)$ than $\mathrm{Cr}^{3+}$ $\left(0.52 \mathrm{~A}^{\circ}\right)($ Faur-Brasquet, Reddad et al. 2002).

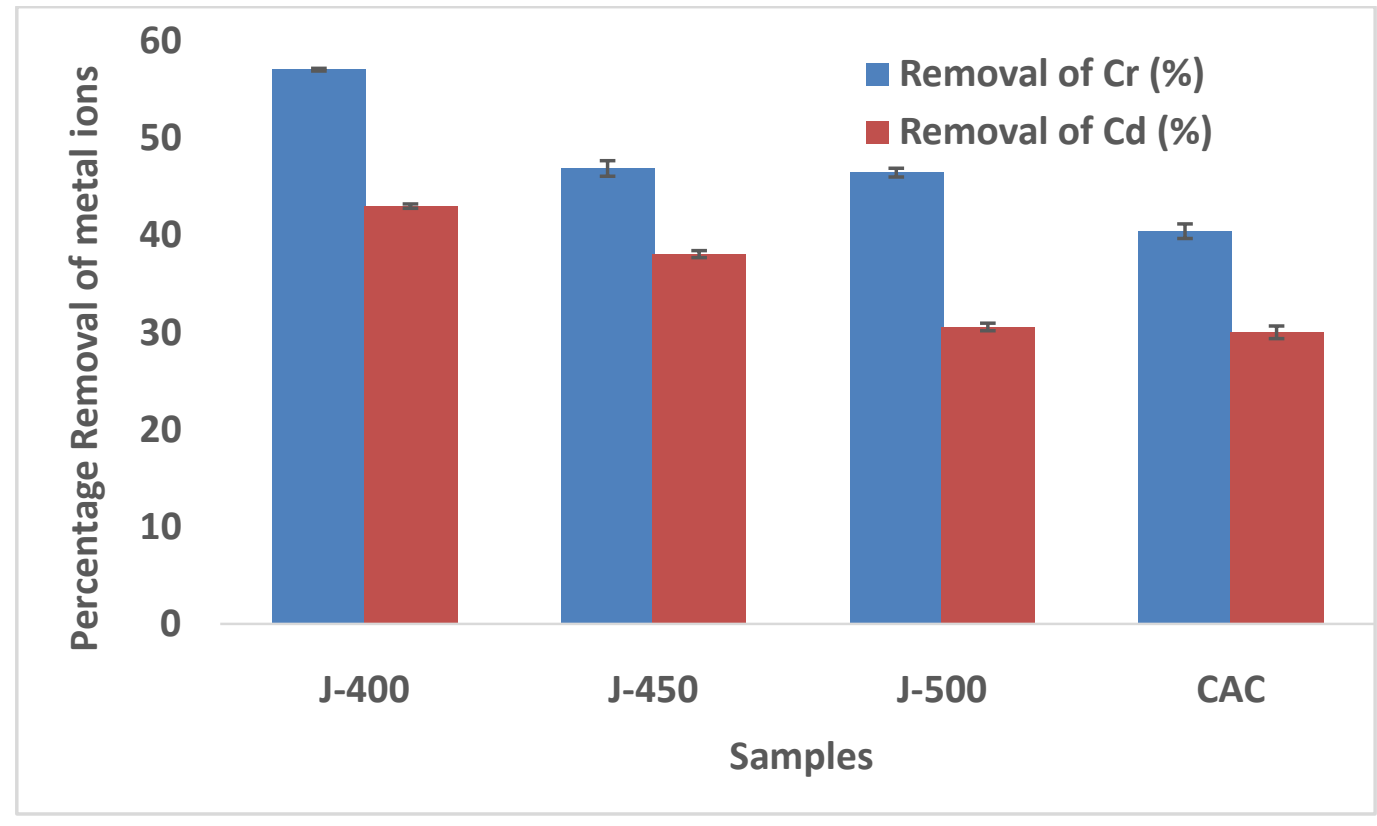

Figure 6: Removal yield of heavy metals using different batches of activated carbons produced.

All ACs produced in this study showed better adsorption for both $\mathrm{Cr}^{3+}$ and for $\mathrm{Cd}^{2+}$ in comparison to CAC. However, J-400 showed the best removal yield among all adsorbents. In comparison to CAC, J-400 showed statistically significantly higher removal at $16.63 \%(\mathrm{P}<0.001)$ for $\mathrm{Cr}^{3+}(57.06 \%)$ and $12.9 \%(\mathrm{P}<0.001)$ for $\mathrm{Cd}^{2+}$ (43.01\%) (see Table 3). This could be potentially to be due to the fact thatfor produced ACs, the amount of micropores which is mainly responsible for adsorption, decreases with increasing charring temperature. So the best removal yields was obtained by the adsorbent $\mathrm{J} 400$ andwas used for further experiments as the best suitable adsorbent.Variables ( $\mathrm{pH}$,adsorbent doses and time)that affect the adsorption process were further studied for J-400.

Table 3: Comparison for percentage removal of heavy metal using $\mathrm{J}-400$ and $\mathrm{CAC}$

\begin{tabular}{|c|c|c|c|c|c|}
\hline Adsorbent & J-400 & CAC & \% difference & P value & Statistically significancant \\
\hline$\%$ removal of Cr & 57.06 & 40.43 & 16.63 & $<0.001$ & yes \\
\hline$\%$ removal of Cd & 43.01 & 30.02 & 12.9 & $<0.001$ & yes \\
\hline
\end{tabular}

\subsubsection{Effect of $\mathrm{pH}$ on adsorption of $\mathrm{J}-400$}

$\mathrm{pH}$ is one of the most important parameters to control the adsorption of heavy metals from the solution. Figure 7revealed that the percentage removal of $\mathrm{Cr}^{3+}$ and $\mathrm{Cd}^{2+}$ increases as $\mathrm{pH}$ increases upto a certain value. The highest percentage removal $(89 \%)$ of $\mathrm{Cr}^{3+}$ was obtained at $\mathrm{pH} 6$ and for $\mathrm{Cd}^{2+} 88 \%$ removal was found around $\mathrm{pH} 8$. 
However, for both metal ions a decrease in percentage removal was observed at higher $\mathrm{pH}$,for $\mathrm{Cr}^{3+}$ the value decreased to $40 \%$ at $\mathrm{pH} 8$ and for $\mathrm{Cd}^{2+}$ the value decreased to $65 \%$ at $\mathrm{pH} 10$.

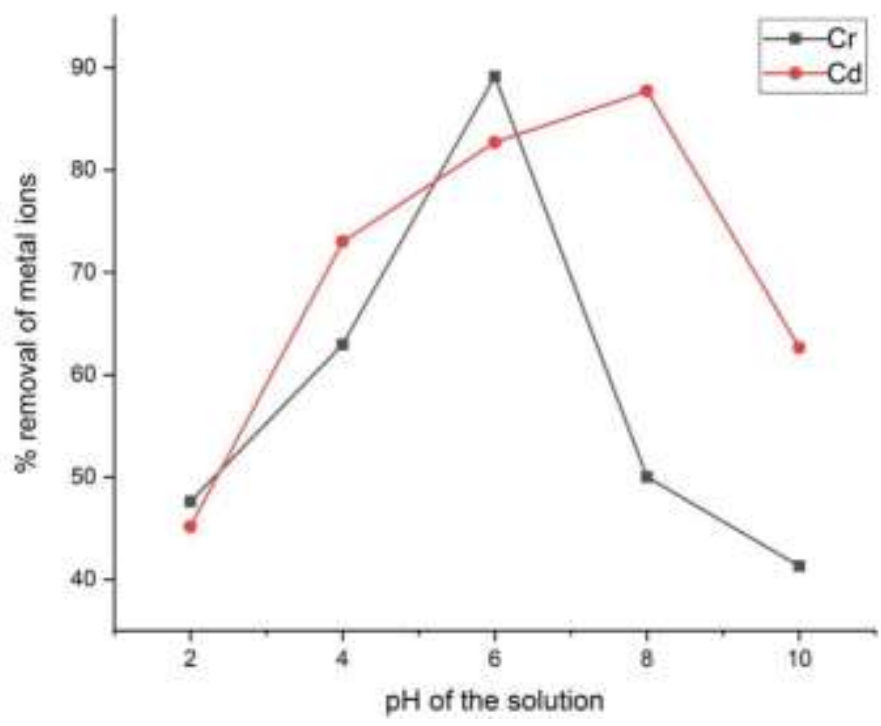

Figure 7: Effect of $\mathrm{pH}$ on the percentage removal of metal ions by J-400.

For instance, by using $400 \mathrm{mg}$ of $\mathrm{J}-400$ for $25 \mathrm{ml}$ solution, we found almost $90 \%$ adsorption for $\mathrm{Cr}^{3+}$ and $88 \%$ adsorption for $\mathrm{Cd}^{2+}$.

Adsorption of metal ions at different $\mathrm{pH}$ depends on the amount of metal ion distribution in prepared solution and also on the nature of the adsorbent surface. For instance, atlower pH ( 2 to 4$)$, the predominant cations of $\mathrm{Cr}$ (III) are $\mathrm{Cr}^{3+}, \mathrm{CrOH}^{2+}, \mathrm{CrOH}_{2}{ }^{+}$. Moreover, inlowerpH the surface of the adsorbent becomes protonated and hence there is a decrease in the electrostatic attraction between the $\mathrm{Cr}^{3+}$ ion and the adsorbent surface which causes a decrease in percentage removal of $\mathrm{Cr}^{3+}-$ ion $^{(\mathrm{Wu} \text {, Zhang et al. 2008, Wang, Wang et al. 2010) }}$. So, better adsorption is expected at higherpH $(<6)$, since at that condition, the adsorbent surface would be less protonatedand would have strong attraction for cationic species.However, when $\mathrm{pH}$ exceeds the value 6 , the value decrease which might be due to the decrease in adsorption by $\mathrm{Cr}^{3+}$ ion, however, ions still removes at that $\mathrm{pH}$ is that cr ions get precipitated from the solution in that $\mathrm{pH}$ range.in the prepared solution which ultimately again resulted in a decrease in adsorption. So an optimum $\mathrm{pH}$ of 6 is suggested for better adsorption of $\mathrm{Cr}$ with adsorbent $\mathrm{J}-400$.

Similarly for cadmium adsorption, $\mathrm{Cd}$ species are found to be present in deionized water in the forms of $\mathrm{Cd} 2+, \mathrm{Cd}(\mathrm{OH})+, \mathrm{Cd}(\mathrm{OH}) 20, \mathrm{Cd}(\mathrm{OH}) 2(\mathrm{~s})$, at $\mathrm{pH} 8$, the percentage removal of $\mathrm{Cd}^{2+}$ was highest at $88 \%$. However, at $\mathrm{pH}>8$, percentage removal of $\mathrm{Cd}^{2+}$ ion decreased to $\sim 65 \%$. This might be due to the fact that at $\mathrm{pH}>8$, the adsorption of $\mathrm{AC}$ capacity decreased and of $\mathrm{Cd}^{2+}$ ion alsostarted to precipitatefrom the solution in the form of $\mathrm{Cd}(\mathrm{OH})_{2}$ (Mohammad, Akram et al. 2017). Wang et al. used adsorb bamboo charcoal to precipitate cd ion and also reported highest percentage removal ofcd ion by bamboo charcoal dominantly controlled by adsorption at $\mathrm{pH}$ values 


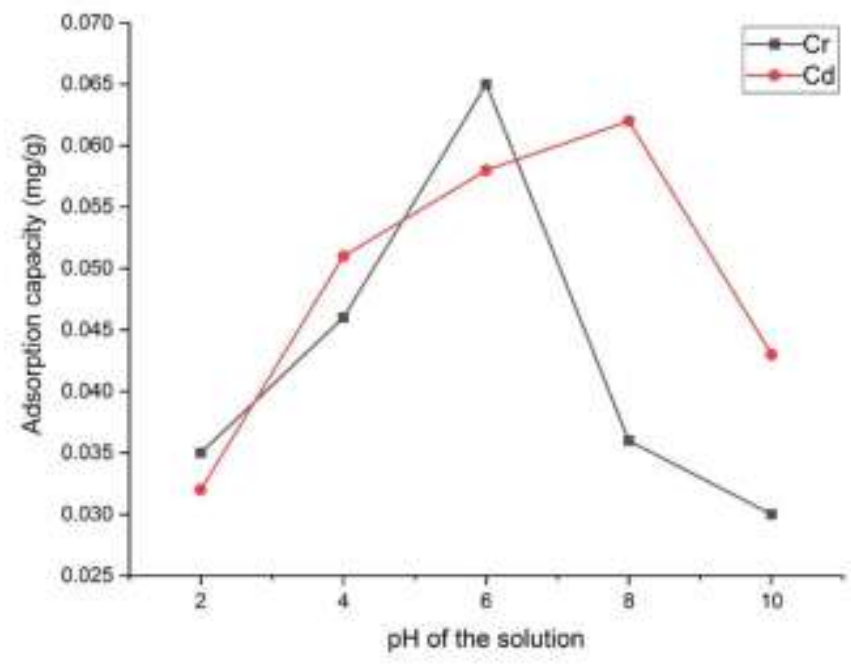

Figure 8:Effect of pH on adsorption capacity of J-400.

\subsection{Effect of adsorbent dosage on adsorption}

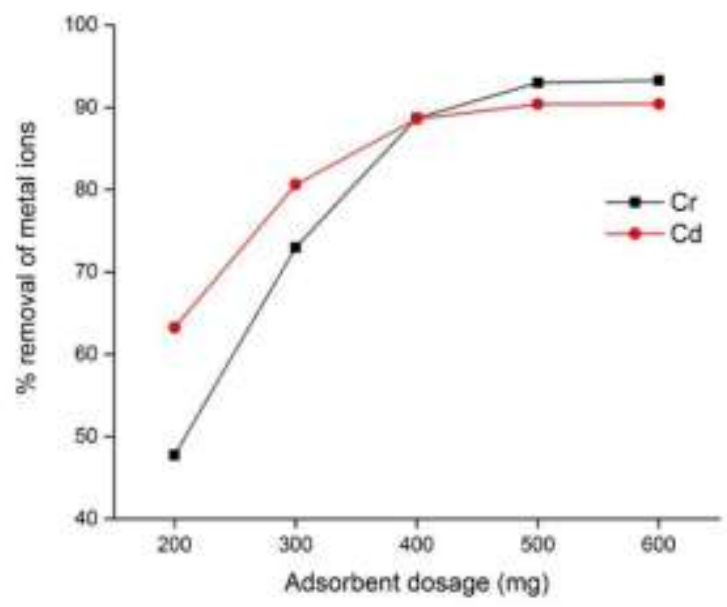

Figure 9:Effect of adsorbent dose on the \% removal of metal ions by J-400.

Figure 9 shows the effect of different adsorbent dose in the range $200 \quad 600 \mathrm{mg}$. The $\% \mathrm{removal}^{\mathrm{of}} \mathrm{Cr}^{3+}$ and $\mathrm{Cd}^{2+}$ increased by $45.25 \%$ and $27.18 \%$ respectively with an increase in the adsorbent dosage from 200 to m500g, however, became constant for further increase of adsorbent dosage. The increase in \% removal of metal ions with an increase in adsorbent dosage is to be due to the availability of larger surface area and more adsorption sites(Naiya, Bhattacharya et al. 2009). At adsorbent dosage $>500 \mathrm{mg}$, the absorbent surface get saturated with the metal ions and an equilibrium establish between the concentration of the metal ions in the surface of the adsorbent and in the solution. Naiya et al. (Naiya, Bhattacharya et al. 2009)also reported an increase in percentage removal of Cd2+ ion an increase in ion removal increased upto $8 \mathrm{gm} / \mathrm{L}$ adsorbent, however, this value remain constant on increasing the value up to $32 \mathrm{~g} / \mathrm{L}$. 
Thus, after a certain dosage, increased adsorbent dosage did not enhance the removal percentage of metal ions.

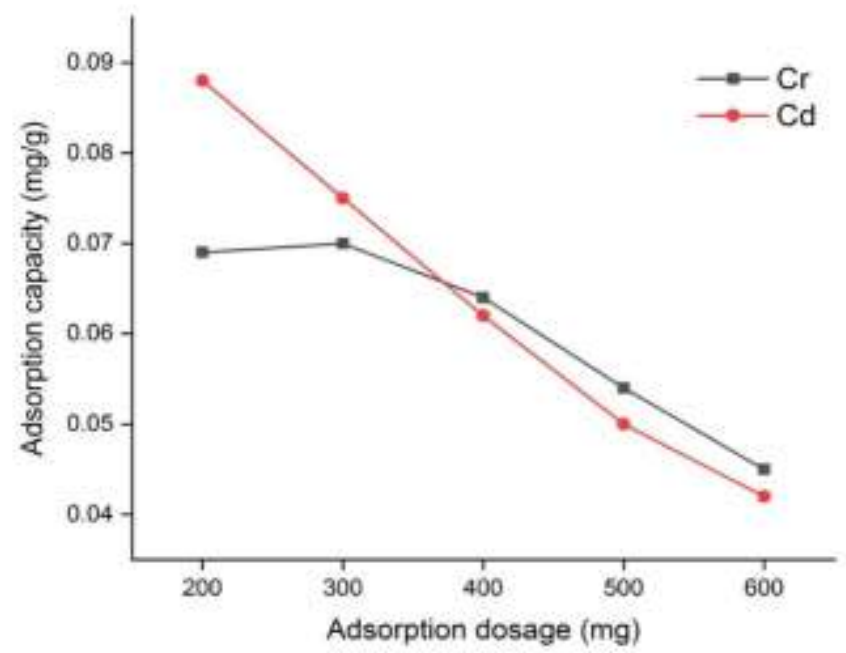

Figure 10: Effect of adsorption dosage on adsorption capacity of J-400.

Figure 10shows a decrease in adsorption capacity by $34.7 \%$ and $52.27 \%$ for $\mathrm{Cr}$ and $\mathrm{Cd}$ respectively with an increase in the adsorption dose from 200 to $600 \mathrm{mg}$. The decrease in adsorption capacity with increase in the adsorbent dose is mainly to be due to the unsaturation of adsorption sites during the adsorption process(Wang, Wang et al. 2010). Another explanation could be the particle interactions, for example aggregation results from high adsorbent concentration which would eventually causes a decrease in the total surface areaof the adsorbent and in turn the adsorption capacity(Rao, Rao et al. 2008).

From the above discussion, it can be said that although the percentage removal of $\mathrm{Cr}^{3+}$ and $\mathrm{Cd}^{2+}$ increases (Figure 9) with increased amount of adsorbent, however the adsorption capacity decreases (

Figure 10) for $25 \mathrm{ml}$ solution. So, it can be suggested that, using a high amount of adsorbent will not be economical.

For instance, From the Figure 9and

Figure 10 it can be observed that for $\mathrm{Cr}^{3+}$ ion, using $300 \mathrm{mg}$ adsorbent, the highest adsorption capacity of $\mathrm{J}$ 400 was $0.07 \mathrm{mg} / \mathrm{g}$ and the percentage removal of $\mathrm{Cr}^{3+}$ ion was $73 \%$. On the other hand, using $400 \mathrm{mg} \mathrm{J}-400$, the adsorption capacity was found to be $0.064 \mathrm{mg} / \mathrm{g}$ and the percentage removal of $\mathrm{Cr}^{3+}$ ion was $88 \%$. So it can be said that on using $400 \mathrm{mg}$ adsorbent, although adsorption capacity decreased by $8.5 \%$ sorbent, however removal efficiency increased by $15.69 \%$. So using $400 \mathrm{mg}$ adsorbent can be suggested to be the best economic approach.

Similarly for $\mathrm{Cd}^{2+}$ ion, using $200 \mathrm{mg}$ adsorbent, the highest adsorption capacity of $\mathrm{J}-400 \mathrm{was} .088 \mathrm{mg} / \mathrm{g}$ and the percentage removal for $\mathrm{Cd}^{2+}$ ion was $63.24 \%$. On the other hand, using $300 \mathrm{mg}$ adsorbent although adsorption capacity decreased to $0.075 \mathrm{mg} / \mathrm{g}$, however percentage removal increased to $80.63 \%$.So, for $\mathrm{Cd}^{2+}$ ion, it can be 
suggested that using $300 \mathrm{mg}$ adsorbent will be the best economical approach since $17 \%$ higher removal yield was found in comparison to using $200 \mathrm{mg}$ adsorbent.

\subsubsection{Effect of contact time on adsorption}

Contact time is another important factor that influences the adsorption since it provides information on the adsorption and desorption efficiency. It is the time which corresponds to the adsorption equilibrium. The effect of contact time on the adsorption for a time varying from 1 to 6 hours is presented in Figure 11.

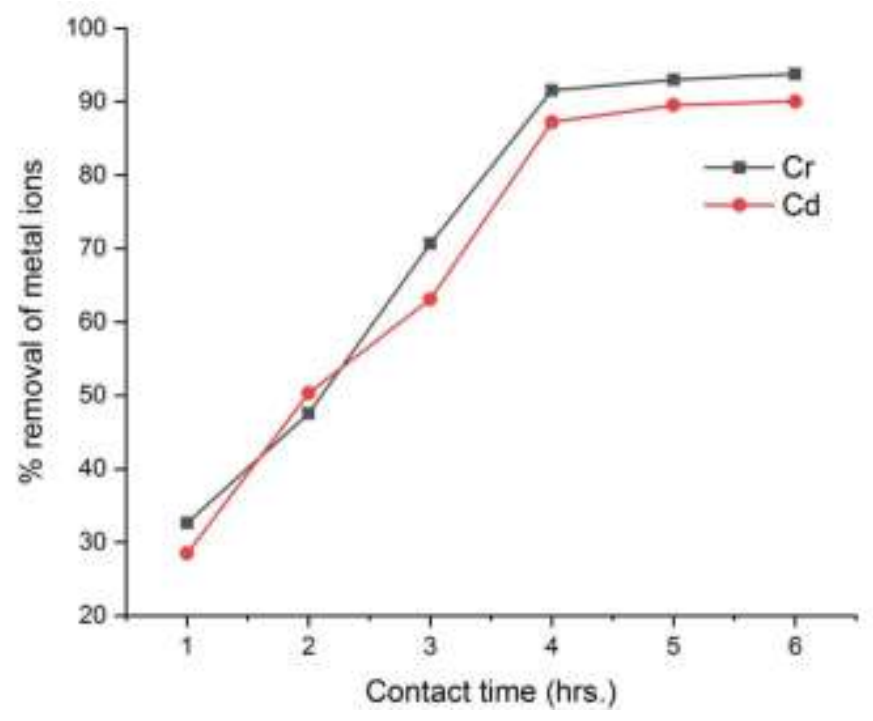

Figure 11: Effect of contact time on adsorption by J-400.

From Figure 11 it can be observed that, in the first hour the percentage removal of $\mathrm{Cr}$ and $\mathrm{Cd}$ was around $30 \%$. This value increased gradually up to 4 hours and reached at $91.5 \%$ for $\mathrm{Cr}$ and $87.23 \%$ for Cd at hour 4 . The percentage removal of metal ion remain constant over next 2 hours. The rapid increase in the percentage removal at the initial stage to be due to the high availability of the sorption sites and then reached a constant value due to the saturation of the active site, which did not allow more adsorption to take place(Mohammad, Akram et al. 2017).

\subsection{Adsorption isotherm}

Adsorption isotherm is one of the most important characteristics to describe the adsorption behavior. It also describes equilibrium relationship between the amount of adsorbate adsorbed and the concentration of the adsorbate dissolved in the liquid. Among many isotherm models, the Langmuir isotherm and the Freundlich isotherm were employed in this study to observe the adsorption behavior.

\subsubsection{Langmuir Isotherm}

For a given adsorption process, when the values of $\left(\mathrm{C}_{\mathrm{e}} / \mathrm{q}_{\mathrm{e}}\right)$ are plotted against the corresponding value of $\mathrm{C}_{\mathrm{e}}$, the following curve is obtained.

The equilibrium data were analyzed using, Langmuir model (Eqs. (6), (8) and (9)) to get the isotherm. The isotherm were shown graphically in Fig. 6 and the isotherm parameters were listed in Table 2. All the plots showed a straight line, indicating that the adsorption of $\mathrm{Cd}$ (II) ions follows the isotherms well. Langmuir adsorption isotherm model is presented by Figure 12. The maximum adsorption capacity, $\mathrm{q}_{\max }$ and the Langmuir constant, $\mathrm{K}_{\mathrm{L}}$ 
are calculated from the slope and the intercept respectively. Values obtained for the adsorption of $\mathrm{Cr}$ are listed in table 3

The basic assumption of Langmuir adsorption isotherm is based on monolayer coverage ofthe adsorbate on the surface of adsorbent [26,27], which is an indication of the fact that the adsorption of Cd (II) ions onto bamboo

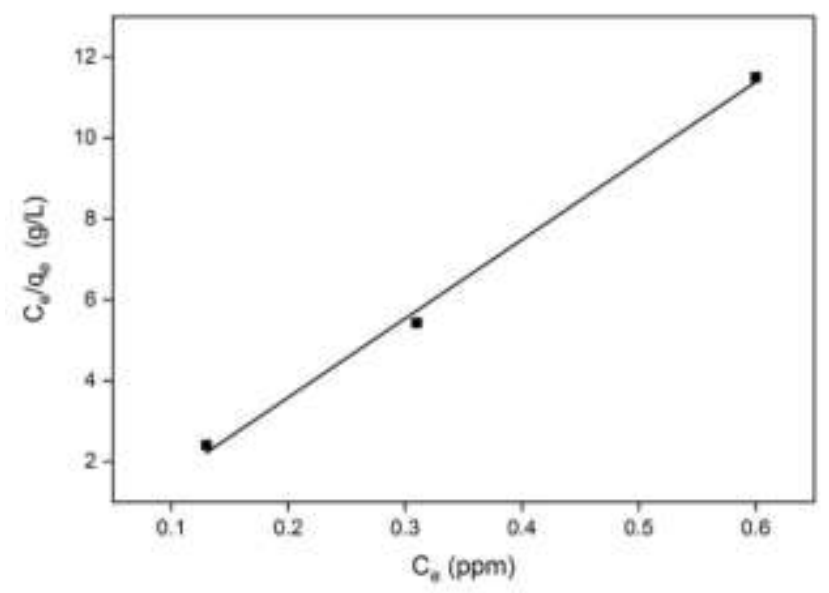

Figure 12: Langmuir adsorption isotherm

\subsubsection{Freundlich isotherm}

The Freundlich isotherm is a popular model used to describe heterogeneous adsorption process, i.e. adsorption that takes place on a heterogeneous surface through a multilayer adsorption mechanism. A graph of -log $\mathrm{q}_{\mathrm{e}} \mathrm{vs}-\log \mathrm{C}_{\mathrm{e}}$ is given in the next page.

A graph of $-\log \mathrm{q}_{\mathrm{e}} \mathrm{vs}-\log \mathrm{C}_{\mathrm{e}}$ is shown below. Figure 4.18 shows the Freundlich adsorption isotherm model. The value of the $\mathrm{K}_{\mathrm{F}}$ and $1 / \mathrm{n}$ can be calculated from the intercepts and slopes of the plot of $-\log \mathrm{q}_{\mathrm{e}} \mathrm{vs}-\log \mathrm{C}_{\mathrm{e}}$. Values obtained are given in table 4.3.

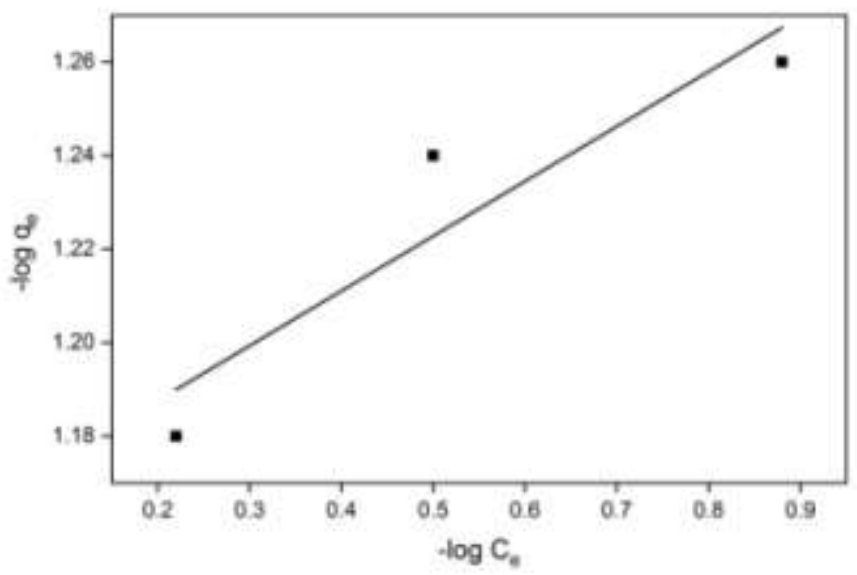


Figure 13: Freundlich adsorption isotherm

Figure 13 shows the Freundlich adsorption isotherm model. The value of the $\mathrm{K}_{\mathrm{F}}$ and $1 / \mathrm{n}$ can be calculated from the intercepts and slopes of the plot of $-\log \mathrm{q}_{\mathrm{e}} \mathrm{vs}-\log \mathrm{C}_{\mathrm{e}}$. Values obtained are given in table 4. When the $1 / \mathrm{n}$ value is between 0.1 and 0.5 , the adsorption process is wonderful. If the value is between 0.5 and 1 , the adsorption process is easy and if the value is greater than 1, it is difficult to adsorb(Dhananasekaran, Palanivel et al. 2016). In our study the value of $1 / \mathrm{n}$ was found 0.117 at room temperature. Therefore, we can conclude that the Freundlich adsorption isotherm is applicable for the adsorption of chromium.

Table 4: Isotherm parameter for the adsorption of $\mathrm{Cr}^{3+}$

\begin{tabular}{|c|c|c|c|}
\hline \multirow{2}{*}{ Langmuir Isotherm } & $\mathrm{q}_{\max }(\mathrm{mg} / \mathrm{g})$ & $\mathrm{R}_{\mathrm{L}}$ & $\mathrm{R}^{2}$ \\
\cline { 2 - 4 } & 0.0512 & .006 & .993 \\
\hline \multirow{2}{*}{ Freundlich Isotherm } & $\mathrm{K}_{\mathrm{F}}(\mathrm{L} / \mathrm{g})$ & $1 / \mathrm{n}$ & $\mathrm{R}^{2}$ \\
\cline { 2 - 4 } & 14.45 & 0.117 & .870 \\
\hline
\end{tabular}

The essential characteristics of Langmuir can be expressed in terms of a dimensionless constant separation factor or equilibrium parameter, $\mathrm{R}_{\mathrm{L}}$ which is defined by:

$$
\mathbf{R}_{\mathrm{L}}=\frac{1}{1+\mathrm{K}_{\mathrm{L}} \mathbf{C}_{\mathbf{0}}}
$$

Where $\mathrm{C}_{0}$ is the highest initial concentration $(\mathrm{ppm})$. The value of $\mathrm{R}_{\mathrm{L}}$ indicates the nature of the adsorption process as given below:

$\mathrm{R}_{\mathrm{L}}>1$, Unfavorable;

$0<\mathrm{R}_{\mathrm{L}}<1$, Favorable;

$\mathrm{R}_{\mathrm{L}}=0$, Irreversible.

From Table 4\&Error! Reference source not found., it is seen that the value of $R_{L}$ is less than 1, which indicated that adsorption is favorable.

Table 5: Comparison of adsorption capacity of the prepared activated carbon compared to other adsorbents to adsorb Chromium (1ppm initial concentration, 400mg adsorbent, $25 \mathrm{ml}$ volume)

\begin{tabular}{|c|c|c|}
\hline Adsorbents & Adsorption capacity (mg/g) & Reference \\
\hline Soya cake & 0.0001 & (Daneshvar, Salari et al. 2002) \\
\hline Coconut shell powder & 0.0004 & (Pino, de Mesquita et al. 2006) \\
\hline Rice bran & 0.0005 & (Singh, Rastogi et al. 2005) \\
\hline Coffee husk & .002 & (Oliveira, Franca et al. 2008) \\
\hline Almond shell & 0.003 & (Dakiky, Khamis et al. 2002) \\
\hline Eucalyptus bark & 0.014 & (Sarin and Pant 2006) \\
\hline Rubber wood sawdust & 0.014 & (Karthikeyan, Rajgopal et al. 2005) \\
\hline
\end{tabular}




\begin{tabular}{|c|c|c|}
\hline Wood activated carbon & 0.028 & (Selomulya, Meeyoo et al. 1999) \\
\hline $\begin{array}{c}\text { Coconut shell activated } \\
\text { carbon }\end{array}$ & 0.038 & (Hamadi, Chen et al. 2001) \\
\hline $\begin{array}{c}\text { Jute fibre activated carbon } \\
(\mathrm{J}-400)\end{array}$ & 0.065 & In this study \\
\hline
\end{tabular}

Prepared activated carbon shows greater adsorption capability than most other adsorbents.

Table 6: Comparison of adsorption capacity of the prepared activated carbon compared to other adsorbents to adsorb Cadmium (1ppm initial concentration, 400mg adsorbent, $25 \mathrm{ml}$ volume)

\begin{tabular}{|c|c|c|}
\hline Adsorbents & Adsorption capacity (mg/g) & Reference \\
\hline Bamboo charcoal & 0.025 & (Ofomaja and Ho 2007) \\
\hline Rice husk & 0.018 & (Kumar and Bandyopadhyay 2006) \\
\hline Corncob & 0.018 & (Reddad, Gerente et al. 2002) \\
\hline Spent grain & 0.036 & (Low, Lee et al. 2000) \\
\hline Sugar beet pulp & 0.035 & (Reddad, Gerente et al. 2002) \\
\hline Bagasse fly ash & 0.013 & (Saeed, Iqbal et al. 2009) \\
\hline Mungbean husk & 0.073 & (Abia, Horsfall Jr et al. 2003) \\
\hline $\begin{array}{c}\text { Cassava waste } \\
\text { (J-400) }\end{array}$ & 0.037 & In this experiment \\
\hline
\end{tabular}

In case of Cadmium adsorption, prepared activated carbon also shows greater adsorption capability than most other adsorbents.

\section{Conclusion}

In this work, six different batches of Activated carbon was prepared from two different raw materials, bagasse and jute fibre at three different temperature $\left(400,450 \& 500{ }^{\circ} \mathrm{C}\right)$ which were successfully used as adsorbents for the adsorption of two heavy metals, $\mathrm{Cr}$ and $\mathrm{Cd}$ from their pure solution. All ACs showed better adsorption for $\mathrm{Cr}$ in

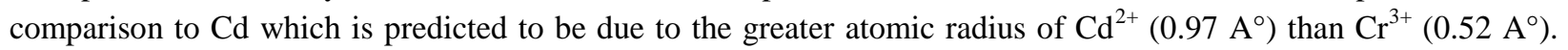
Among all the adsorbents, J-400 showed best adsorption efficiency for both metals. Adsorption process was carried out by changing different parameters such as $\mathrm{pH}$, adsorbent dose and contact time. The percentage removal of both metal ions increased with the increase of $\mathrm{pH}$ of the solution up to a certain value. For $\mathrm{Cr}^{3+}$ solution, best result was obtained at $\mathrm{pH} 6$ and for $\mathrm{Cd}^{2+}$ solution at $\mathrm{pH}$ 8. If the $\mathrm{pH}$ of the solution was further increased, the metal ions got precipitated which ultimately again resulted a decrease in adsorption. So an optimum $\mathrm{pH}$ of 6 is suggested for better adsorption of $\mathrm{Cr}$ and $\mathrm{pH} 8$ is suggested for better adsorption of $\mathrm{Cd}$ with adsorbent $\mathrm{J}-400$.

It has also been observed that percentage removal of $\mathrm{Cr}$ and $\mathrm{Cd}$ ions increased with increasing contact time. However, as the contact time increased, the percentage removal became constant. For example, upon using $400 \mathrm{mg}$ of J-400 adsorbent for $25 \mathrm{ml}$ solution, as contact time increased from 4 to 5 hours, a small and insignificant increase 
in removal yields was observed for both metal ions $\left(1.5 \%\right.$ for $\mathrm{Cr}^{3+}$ and by $2.2 \%$ for $\left.\mathrm{Cd}^{2+}\right)$. So for $25 \mathrm{ml}$ solution of both metal ions, 4 hours contact time would be preferable.

In Bangladesh, the effluents from tannery industry and other industries are highly concentrated with chromium, cadmium and other heavy metals which are deliberately disposed to the river without any pretreatment. This is a very alarming situation to our health as well as to the aquatic life and for environment. In this regard, the activated carbon produced from this study could be an effective and potential adsorbent to remove heavy metals from industrial effluent and thereby to save our environment.

\section{REFERENCES}

[1] Abia, A., M. Horsfall Jr and O. Didi (2003). "The use of chemically modified and unmodified cassava waste for the removal of Cd, Cu and Zn ions from aqueous solution." Bioresource Technology 90(3): 345-348.

[2] Asadullah, M., M. Asaduzzaman, M. S. Kabir, M. G. Mostofa and T. J. J. o. h. m. Miyazawa (2010). "Chemical and structural evaluation of activated carbon prepared from jute sticks for Brilliant Green dye removal from aqueous solution." 174(1-3): 437-443.

[3] Asadullah, M., I. Jahan, M. B. Ahmed, P. Adawiyah, N. H. Malek, M. S. J. J. o. I. Rahman and E. Chemistry (2014). "Preparation of microporous activated carbon and its modification for arsenic removal from water." 20(3): 887-896.

[4] Asadullah, M., M. A. Rahman, M. A. Motin, M. B. J. J. o. S. S. Sultan and Technology (2007). "Adsorption studies on activated carbon derived from steam activation of jute stick char." 23(1/2): 73.

[5] Auta, M. and B. Hameed (2011). "Optimized waste tea activated carbon for adsorption of Methylene Blue and Acid Blue 29 dyes using response surface methodology." Chemical Engineering Journal 175: 233-243.

[6] Bansal, R. C., D. Aggarwal, M. Goyal and B. C. Kaistha (2002). Influence of carbon-oxygen surface groups on the adsorption of phenol by activated carbons.

[7] Bouchelta, C., M. S. Medjram, O. Bertrand and J.-P. Bellat (2008). "Preparation and characterization of activated carbon from date stones by physical activation with steam." Journal of Analytical and Applied Pyrolysis 82(1): 70-77.

[8] Chen, Y., L. Peng, Q. Zeng, Y. Yang, M. Lei, H. Song, L. Chai and J. Gu (2015). "Removal of trace Cd (II) from water with the manganese oxides/ACF composite electrode." Clean Technologies and Environmental Policy 17(1): 49-57.

[9] Cuhadar, C. (2005). Production and Characterization of Activated Carbon from Hazelnut Shell and Hazelnut Husk, M.Sc. Thesis, The Graduate School of Natural and Applied sciences of Middle East Technical University.

[10] Dakiky, M., M. Khamis, A. Manassra and M. Mer'Eb (2002). "Selective adsorption of chromium (VI) in industrial wastewater using lowcost abundantly available adsorbents." Advances in environmental research 6(4): 533-540.

[11] Daneshvar, N., D. Salari and S. Aber (2002). "Chromium adsorption and Cr (VI) reduction to trivalent chromium in aqueous solutions by soya cake." Journal of Hazardous Materials 94(1): 49-61.

[12] Dhananasekaran, S., R. Palanivel and S. Pappu (2016). "Adsorption of methylene blue, bromophenol blue, and coomassie brilliant blue by $\alpha$-chitin nanoparticles." Journal of advanced research 7(1): 113-124.

[13] Dula, T., K. Siraj and S. A. Kitte (2014). "Adsorption of Hexavalent Chromium from Aqueous Solution Using Chemically Activated Carbon Prepared from Locally Available Waste of Bamboo (Oxytenanthera abyssinica) \%J ISRN Environmental Chemistry." 2014 : 9.

[14] Fan, Y., X. Yang, B. Zhu, P.-F. Liu and H.-T. Lu (2014). "Micro-mesoporous carbon spheres derived from carrageenan as electrode material for supercapacitors." Journal of Power Sources 268: 584-590.

[15] Faur-Brasquet, C., Z. Reddad, K. Kadirvelu and P. Le Cloirec (2002). "Modeling the adsorption of metal ions (Cu2+, Ni2+, Pb2+) onto ACCs using surface complexation models." Applied Surface Science 196(1-4): 356-365.

[16] Foo, K. Y., Lee, L.K. and Hameed, B.H., 2013 "Preparation of activated carbon from sugarcane bagasse by microwave assisted activation for the remediation of semi-aerobic landfill leachate. ." Bioresource technology 134: 166-172.

[17] Girgis, B. S., Khalil, L.B. and Tawfik, T.A., 1994. "Activated carbon from sugar cane bagasse by carbonization in the presence of inorganic acids. Journal of Chemical Technology \& Biotechnology: International Research in Process, ." Environmental AND Clean Technology(61(1)): 87-92.

[18] Hamadi, N. K., X. D. Chen, M. M. Farid and M. G. Lu (2001). "Adsorption kinetics for the removal of chromium (VI) from aqueou s solution by adsorbents derived from used tyres and sawdust." Chemical Engineering Journal 84(2): 95-105. 
[19] Kamal, H. (2014). "Removal of Methylene Blue from aqueous solutions using composite hydrogel prepared by gamma irradiation." Journal of American Science 10(4): 125-133.

[20] Karthikeyan, T., S. Rajgopal and L. R. Miranda (2005). "Chromium (VI) adsorption from aqueous solution by Hevea Brasilinesis sawdust activated carbon." Journal of hazardous materials 124(1-3): 192-199.

[21] Kumar, U. and M. Bandyopadhyay (2006). "Sorption of cadmium from aqueous solution using pretreated rice husk." Bioresource technology 97(1): 104-109.

[22] Low, K., C. Lee and S. Liew (2000). "Sorption of cadmium and lead from aqueous solutions by spent grain." Process Biochemistry 36(1-2): 59-64.

[23] M.S. Shamsuddin, N. R. N. Y., M.A. Sulaiman, (2016). "Synthesis and Characterization of Activated Carbon Produced from Kenaf Core Fiber Using H3PO4 Activation, Procedia Chemistry." Procedia Chemistry 19: 558-565.

[24] McKee, M. G., S. Unal, G. L. Wilkes and T. E. Long (2005). "Branched polyesters: recent advances in synthesis and performance." Progress in polymer science 30(5): 507-539.

[25] Mohammad, R., H. Akram and H. Rim (2017). "Removal of Cadmium (II) Ions from Waste Water by Adsorption onto the Powder of Lebanese Anacyclus nigllifolius Boiss: A Comparative Study." Am J Phytomedicine Clin Ther 5: 1.

[26] Naiya, T. K., A. K. Bhattacharya and S. K. Das (2009). "Adsorption of Cd (II) and Pb (II) from aqueous solutions on activated alumina." Journal of colloid and interface science 333(1): 14-26.

[27] Ofomaja, A. E. and Y.-S. Ho (2007). "Effect of pH on cadmium biosorption by coconut copra meal." Journal of Hazardous Materials 139(2): 356-362.

[28] Oliveira, L. S., A. S. Franca, T. M. Alves and S. D. Rocha (2008). "Evaluation of untreated coffee husks as potential biosorbents for treatment of dye contaminated waters." Journal of Hazardous Materials 155(3): 507-512.

[29] Pino, G., L. S. de Mesquita, M. Torem and G. Pinto (2006). "Biosorption of heavy metals by powder of green coconut shell." Separation Science and Technology 41(14): 3141-3153.

[30] Ramesh, T., N. Rajalakshmi, K. S. J. R. E. Dhathathreyan and E. Sustainability (2017). "Synthesis and characterization of activated carbon from jute fibers for hydrogen storage." 2: 4 .

[31] Rao, M. M., G. C. Rao, K. Seshaiah, N. Choudary and M. Wang (2008). "Activated carbon from Ceiba pentandra hulls, an agricultural waste, as an adsorbent in the removal of lead and zinc from aqueous solutions." Waste Management 28(5): 849-858.

[32] Reddad, Z., C. Gerente, Y. Andres and P. Le Cloirec (2002). "Adsorption of several metal ions onto a low-cost biosorbent: kinetic and equilibrium studies." Environmental science \& technology 36(9): 2067-2073.

[33] Saeed, A., M. Iqbal and W. H. Höll (2009). "Kinetics, equilibrium and mechanism of Cd2+ removal from aqueous solution by mungbean husk." Journal of hazardous materials 168(2-3): 1467-1475.

[34] Sarin, V. and K. K. Pant (2006). "Removal of chromium from industrial waste by using eucalyptus bark." Bioresource technology 97(1): $15-20$.

[35] Selomulya, C., V. Meeyoo and R. Amal (1999). "Mechanisms of Cr (VI) removal from water by various types of activated carbons." Journal of Chemical Technology \& Biotechnology: International Research in Process, Environmental \& Clean Technology 74(2): 111-122.

[36] Singh, K., R. Rastogi and S. Hasan (2005). "Removal of Cr (VI) from wastewater using rice bran." Journal of Colloid and Interface Science 290(1): 61-68.

[37] Srivastava, V. C., I. D. Mall and I. M. Mishra (2008). "Adsorption of toxic metal ions onto activated carbon: Study of sorption behaviour through characterization and kinetics." Chemical Engineering and Processing: Process Intensification 47(8): 1269-1280.

[38] Wang, F. Y., H. Wang and J. W. Ma (2010). "Adsorption of cadmium (II) ions from aqueous solution by a new low-cost adsorbentBamboo charcoal." Journal of hazardous materials 177(1-3): 300-306.

[39] Wang, F. Y., H. Wang and J. W. J. J. o. h. m. Ma (2010). "Adsorption of cadmium (II) ions from aqueous solution by a new low-cost adsorbent—Bamboo charcoal." 177(1-3): 300-306.

[40] Wu, Y., S. Zhang, X. Guo and H. Huang (2008). "Adsorption of chromium (III) on lignin." Bioresource technology 99(16): 7709-7715.

[41] Yagsi, N. U. (2004). "Production and characterization of activated carbon from apricot stones." A Thesis Submited to the Graduate School of Natural and Applied Science of the Middle East Technical University.

[42] Zhang, X., B. Wang, J. Yu, X. Wu, Y. Zang, H. Gao, P. Su and S. Hao (2018). "Three-dimensional honeycomb-like porous carbon derived from corncob for the removal of heavy metals from water by capacitive deionization." RSC Advances 8(3): 1159-1167. 